\title{
DETERMINANTS OF RENEWABLE ENERGY ADOPTION IN CHINA AND INDIA: A COMPARATIVE ANALYSIS
}

\author{
Shuddhasattwa Rafiq ${ }^{a}$ \\ Curtin University \\ Harry Bloch ${ }^{\mathrm{b}}$ \\ Curtin University \\ $\&$ \\ Ruhul Salim ${ }^{\mathrm{c}}$ \\ Curtin University
}

${ }^{\mathrm{b}}$ Corresponding Author: School of Economics and Finance, Curtin Business School, Curtin University, Perth WA 6845, Australia. E-mail: Harry.Bloch@ cbs.curtin.edu.au Telephone: 61-8-92662035, Facsimile: 61-892663026.

${ }^{\mathrm{a}}$ School of Economics and Finance, Curtin Business School, Curtin University, Perth, WA 6845, Australia. Email: $\underline{\text { S.Rafiq@ } @ \text { curtin.edu.au. }}$

${ }^{\mathrm{c}}$ School of Economics and Finance, Curtin Business School, Curtin University, Perth, WA 6845, Australia. Email: Ruhul.Salim@cbs.curtin.edu.au 


\title{
DETERMINANTS OF RENEWABLE ENERGY ADOPTION IN CHINA AND INDIA: A COMPARATIVE ANALYSIS
}

\begin{abstract}
This article examines the dynamic relationships between output, carbon emission, and renewable energy generation of India and China during the period 1972-2011 using a multivariate vector error correction model. The results for India reveal unidirectional short-run causality from carbon emission to renewable energy generation and from renewable energy generation to output, whereas in the long run the variables have bidirectional causality. Causalities in China give a rather different scenario, with a short-run unidirectional causality from output to renewable energy and from carbon emission to renewable energy generation. In the long run for China, unidirectional causality is found from output to renewable energy generation, while bidirectional causality is found between carbon emission and renewable energy generation.
\end{abstract}

Key Words: Renewable energy, $\mathrm{CO}_{2}$ emission, Time series data, Vector error correction model, Causality

JEL Classifications: C22, C32, Q20, Q43, Q48 


\section{DETERMINANTS OF RENEWABLE ENERGY ADOPTION IN CHINA AND INDIA: A COMPARATIVE ANALYSIS}

\section{Introduction}

The increasing threat of climate change and global warming per se has called for more discussion regarding the linkage between economic growth and pollutant emission all over the world. Carbon dioxide $\left(\mathrm{CO}_{2}\right)$ is considered to be the main greenhouse gas (GHG) leading to global warming (The World Bank, 2007). $\mathrm{CO}_{2}$ emissions have the nature of the 'tragedy of the commons' and an emerging economy may not be interested in reducing $\mathrm{CO}_{2}$ emissions during its rapid economic expansion phase. Growing concerns over economic growth, climate change, and energy dependence are nevertheless driving specific policies to support renewable energy sources and more efficient energy usage in some emerging economies so that economic growth can be sustained without exerting harmful impacts on the environment.

The rapid growth of Chinese and Indian economies has accelerated their energy demand, posing a difficult question about how non-renewable energy is to be efficiently used, given its scarcity and substitutability to renewable energy. Recent renewable energy generation data of these two countries show an encouraging increasing trend. Hence, identifying linkages that are behind adoption of cleaner energy at this stage of development is worth academic research.

China emitted approximately $23.99 \%$ of the world's total carbon dioxide $\left(\mathrm{CO}_{2}\right)$ in 2009 (The World Bank, 2011). This may be attributed to two reasons. The first reason is China's enormous use of fossil fuels, particularly coal. Second, China's consumption of nonfossil energy (i.e. hydro and nuclear electricity) accounted for only $8.6 \%$ of its total energy consumption. The hope for the future is that China's energy consumption policy will follow the philosophy of reducing the overall intensity of carbon emissions by increasing the proportion of renewable energy consumption in the total primary energy consumption.

India was responsible for only about $6.18 \%$ of world's carbon emission in 2009 (The World Bank, 2011). Even though India's economy is growing very rapidly, energy is still scarce and the country is not emitting that much $\mathrm{CO}_{2}$ compared to China. This may be attributed by the fact that many Indian rural households are still out of the reach of continuous electrification and many of these households are still reliant on traditional biomass and biogas-type energy sources for their day-to-day living.

In-depth studies identifying the linkage among output, $\mathrm{CO}_{2}$ emission and renewable energy for major emerging economies like China and India are limited in the literature. 
Furthermore, none of the previous studies attempts to compare the drivers behind the increased renewable energy generation in these two economies. Identifying these linkages might help policymakers to accelerate the adoption of cleaner energy in developing economies. We compare the drivers of renewable energy adoption in two most prominent emerging economies, China and India, with the aim of analyzing causality within an error correction model formulation. This includes identifying the direction of both short- and longrun causality as well as examining within-sample Granger exogeneity and endogeneity of each variable. Furthermore, to check the robustness of the causality directions and magnitude, we present variance decompositions and impulse response functions that provide information about the interaction among the variables beyond the sample period.

This paper is organized as follows. Section 2 provides a basic overview of the pollutant emission and renewable energy adoption scenario in China and India and a critical review of literature. Section 3 delineates the theoretical settings and empirical methodology employed in this paper. Empirical results are offered in Section 4. Sections 5 and 6 present the findings from generalized impulse response functions and variance decompositions, respectively. Finally, the conclusions and discussion of policy implications are offered in Section 7.

\section{Literature Review}

With sustained economic growth for more than three decades, China and India both have lifted millions of people out of poverty. However, these higher economic growth trends have their costs, as well. One of the triple bottom lines, environmental sustainability, is threatened in recent years. The trend of carbon emission for both of these countries shows an increasing pattern over the period from 2003 to 2011, while renewable energy generation in China is rapidly increasing and is also rising in India.

Global new investment in renewable power and fuels was USD 244 billion in 2012, down $12 \%$ from the previous year's record [Table 1]. This decline in investment-after several years of growth - resulted from uncertainty about support policies in major developed economies, especially in Europe (down 36\%) and the United States (down 35\%). The year 2012 saw the most extreme shift yet in the balance of investment activity between developed and developing economies. Outlays in developing countries reached USD 112 billion, representing $46 \%$ of the world total. This was up from $34 \%$ in 2011 , and continued an unbroken eight-year growth trend. By contrast, investment in developed economies fell 29\% to USD 132 billion, the lowest level since 2009. The shift was primarily driven by reductions in subsidies for solar and wind project development in Europe and the United States, increased investor interest in emerging markets with rising power demand and attractive 
renewable energy resources, and falling technology costs of wind and solar PV. Europe and China accounted for $60 \%$ of global investment in 2012 [REN21 2013].

At the national level, the top investors in renewable energy included four developing countries (most of the BRICS countries) and six developed countries. China was in the lead with USD 64.7 billion invested, followed by the United States (USD 34.2 billion), Germany (USD 19.8 billion), Japan (USD 16.0 billion), and Italy (USD 14.1 billion). The subsequent five were the United Kingdom (USD 8.8 billion), India (USD 6.4 billion), South Africa (USD 5.7 billion), Brazil (USD 5.3 billion), and France (USD 4.6 billion). ${ }^{1}$

\section{Table 1: Global Renewable Energy Investment Trend}

\begin{tabular}{|c|c|c|c|c|}
\hline & & 2010 & 2011 & 2012 \\
\hline Investment in new renewable energy capacity (annual) $^{1}$ & Billion USD & 227 & 279 & 244 \\
\hline Renewable power capacity (total, including hydro) & GW & 1,250 & 1,355 & 1,470 \\
\hline Hydropower capacity (total) ${ }^{2}$ & GW & 935 & 960 & 990 \\
\hline Bio-power generation & GWh & 313 & 335 & 350 \\
\hline Solar PV capacity (total) & GW & 40 & 71 & 100 \\
\hline Concentrating solar thermal power (total) & GW & 1.1 & 1.6 & 2.5 \\
\hline Wind power capacity & GW & 198 & 238 & 283 \\
\hline Solar hot water capacity (total) ${ }^{3}$ & $\mathrm{GW}_{\mathrm{th}}$ & 195 & 223 & 255 \\
\hline Ethanol production (annual) & Billion litres & 85.0 & 84.2 & 83.1 \\
\hline Biodiesel production (annual) & Billion litres & 18.5 & 22.4 & 22.5 \\
\hline
\end{tabular}

China accounted for USD 66.6 billion (including R\&D) of renewable energy new investment, up 22\% from 2011 levels, driven by strong growth in the solar power sector, including both utility-scale ${ }^{2}$ and small-scale projects $(<1 \mathrm{MW})$. New renewable energy investment in India has also been increasing till 2011 (USD 13 billion in 2011). However, like some developed countries the investment dropped down to USD 6.5 billion. The trend in investment for last decade nevertheless has been upward as a whole.

Both India and China aspire to increase renewable energy use as both of them are working towards lowering growth in carbon emissions. Some of the major targets in this regard are presented in Table 2.

\footnotetext{
${ }^{1}$ National investment totals do not include government and corporate R\&D because such data are not available for all of these countries.

${ }^{2}$ Utility-scale refers to wind farms, solar parks, and other renewable power installations of $1 \mathrm{MV}$ or more in size, and biofuel plants with capacity of more than 1 million liters.
} 
A substantial and growing amount of literature has studied the nexus between energy consumption and economic growth (for example, Kraft and Kraft, 1978; Ghosh, 2002; Zamani, 2007; Ma et al. 2008; Wolde-Rufael, 2009; Apergis and Payne, 2009; Bloch, et al. 2012; Apergis and Tang, 2013; and Salamaliki and Venetis, 2013). Research on this issue has primarily evolved around two different procedures, the supply-side and the demand-side approaches. The supply-side approach analyses the contribution of energy consumption in economic activities within the traditional production function framework (Stern, 2000; Ghali and El-Sakka, 2004; Oh and Lee, 2004; Sari and Soytas, 2007). While the demand-side approach investigates the relationship between energy consumption, gross domestic product (GDP) and energy prices (often taking CPI as a proxy) in a tri-variate energy demand model (Masih and Masih, 1997; Asafu-Adjaye, 2000; Narayan and Singh, 2007; Rafiq and Salim, 2009). ${ }^{3}$

Table 2: Renewable Energy Targets in India and China

\begin{tabular}{lll}
\hline Country & Sector/Technology & Target \\
\hline India & Renewable electricity & $53 \mathrm{GW}$ capacity by 2017 \\
& Wind & $5 \mathrm{GW}$ by 2017 \\
& Solar & $10 \mathrm{GW}$ by $2017 ; 20 \mathrm{GW}$ grid-connected by $2022 ; 2,000 \mathrm{MW}$ \\
& & off-grid by $2020 ; 20$ million solar lighting systems by 2022. \\
& Small-scale hydro & $2.1 \mathrm{GW}$ by 2017 \\
& Bioenergy & $2.7 \mathrm{GW}$ by 2017 \\
& Solar water heating & $5.6 \mathrm{GW}$ th $\left(8\right.$ million $\left.\mathrm{m}^{2}\right)$ of new capacity to be added between \\
& & 2012 and 2017. \\
China & Renewable electricity & $49 \mathrm{GW}$ capacity by 2013 \\
& Wind & $100 \mathrm{GW}$ on-grid by $2015 ; 200 \mathrm{GW}$ by 2020 \\
& Solar PV & $10 \mathrm{GW}$ in $2013 ; 20 \mathrm{GW}^{2}$ by 2015 \\
CSP & $1 \mathrm{GW}$ by 2015 \\
Hydro & $290 \mathrm{GW}$ by 2015 \\
Bioenergy & $13 \mathrm{GW}$ by 2015 \\
Solar thermal & $280 \mathrm{GW}$ th $\left(400\right.$ million $\mathrm{m}^{2}$ ) by 2015 \\
\hline
\end{tabular}

Source: REN21

Although pollutant emission is a very important component of growth-energy dynamics, many of the earlier studies don't include emission in their models. Some studies that include carbon emission in their analytical frameworks are Ang (2007), Apergis and Payne (2009), Chandran and Tang (2013) and Liu (2005). Arouri et al. (2012) extend the

\footnotetext{
${ }^{3}$ In addition to the above studies, recent research, such as Ang (2008), include pollutant emissions in their analyses to investigate the relationship between energy consumption and economic activities. However, since Ang does not include prices in the models, this is not a complete demand-side model.
} 
findings of Ang (2007), and Apergis and Payne (2009), by implementing recent bootstrap panel unit root tests and cointegration techniques to investigate the relationship among carbon dioxide emissions, energy consumption, and real GDP for 12 Middle East and North African Countries (MENA) over the period 1981-2005. Results show that, in the long run, energy consumption has a positive significant impact on $\mathrm{CO}_{2}$ emissions. More interestingly, it is shown that real GDP exhibits a quadratic relationship with $\mathrm{CO}_{2}$ emissions for the region as a whole.

Pao and Tsai (2010) also employ a panel cointegration framework to examine linkages among pollutant emissions, energy consumption and output for BRIC (Brazil, Russia, India, and China) countries. In the long-run equilibrium, energy consumption has a positive and statistically significant impact on emissions, while real output exhibits the inverted U-shape pattern associated with the Environmental Kuznets Curve (EKC) hypothesis. In the short term, changes in emissions are driven mostly by the error correction term and short-term energy consumption shocks, as opposed to short-term output shocks for each country.

Employing different model settings, Minihan and Wu (2012) study economic structure and strategies for greenhouse gas (GHG) mitigation. Their framework suggests there are different technical options in GHG mitigation due to the economic linkages among different polluting activities. Another study on greenhouse gas emissions, energy consumption and economic growth by Hamit-Haggar (2012) investigates the long-run equilibrium relationship by means of the fully modified OLS (FMOLS) technique proposed by Pedroni (2000), finding that energy consumption has a positive and statistically significant impact on greenhouse gas emissions. In contrast, a non-linear relationship is found between greenhouse gas emissions and economic growth, which is consistent with the environmental Kuznets curve.

One of the recent studies focusing on China and India is Chandran and Tang (2013). This study investigates the short-run and long-run linkages among $\mathrm{CO}_{2}$ emission, economic growth and coal consumption of China and India from 1965 to 2009. This study finds cointegrating relationships between the variables for China. However, this study fails to find any long-run relationship in case of India. Bi-directional causality, in the short and long run, is detected between economic growth and coal consumption as well as between coal consumption and $\mathrm{CO}_{2}$ emissions in China. In addition, uni-directional causality is detected from economic growth to $\mathrm{CO}_{2}$ emissions. For India, this study finds that a short-run bidirectional causality exists between economic growth and $\mathrm{CO}_{2}$ emissions and $\mathrm{CO}_{2}$ and 
between coal consumption. It is also found that economic growth Granger causes coal consumption in the short run in India.

The drivers behind different types of non-renewable energy consumption (i.e. oil, gas and coal) have been well studied, but relatively little is known about the drivers behind renewable energy consumption. Studies that identify the drivers for renewable energy in G7 countries and twenty-two emerging countries are Sadorsky (2009a) and Sadorsky (2009b), respectively. Both these studies employ the panel cointegration technique and find renewable energy consumption is driven by both carbon emissions and GDP in G7 countries, while only GDP is a driver in developing countries. Fang (2011) takes the supply-side approach to investigate the impact of renewable energy in economic development. Using Chinese data spanning from 1978 to 2008, the impact of renewable energy consumption in economic welfare is found to be insignificant. However, none of these studies includes pollutant emission in their models.

Although pollutant emission is directly related to energy generation and renewable energy adoption should have some positive impact on emission scenario, only a few studies of renewable energy include carbon emission in their models including. Salim and Rafiq (2012) employ an autoregressive distribution lag (ARDL) model along with fully modified least square and dynamic ordinary least square models for six major emerging economies, Brazil, China, India, Indonesia, Philippines and Turkey over the period 1980-2006. They find that both income and pollutant emission play a significant role in renewable energy generation in Brazil, China, India and Indonesia while income alone is the main determinant in Philippines and Turkey.

In summary, from the above review it is evident that the relationship among economic growth, carbon emission, and renewable energy generation is not uniform across countries or estimation method. There are few studies of renewable energy consumption in China and India considering emission in analysing the dynamics between renewable energy and output. We utilize recent developments in time-series analysis to examine both the supply and demand approaches for both these countries applying an error correction model on the most recent data. This provides an opportunity to examine similarities and difference in both short- and long-run causality among economic growth, carbon emissions and renewable energy output.

\section{Theoretical Framework}

Variables selected in this study are based on economic theory and data availability. Real GDP is included in the model to measure income; $\mathrm{CO}_{2}$ emission is included for its detrimental 
impact in environment; and renewable energy generation is included to understand the linkages between renewable energy and the other variables. As all the concerned variables can be considered endogenous within a single system, we employ a VAR-type model with three different equations to identify the dynamic relationships among the variables. The equation for economic growth takes the following form:

$$
L Y_{t}=\mu_{i 1}+\sum_{j=1}^{p-1} \beta_{1 j} L Y_{t-j}+\sum_{j=1}^{p-1} \gamma_{1 j} L E R_{t-j}+\sum_{j=1}^{p-1} \delta_{1 j} L C_{t-j}+\varepsilon_{1 t},
$$

where $\mathrm{t}=1972,1973$, 2011 denotes the time period, $\varepsilon_{t}$ is a white noise, 'well behaved' random disturbance term with positive definite covariance matrix $\Omega$. LY, LER and $L C$ refer to the logarithm for real GDP, renewable energy generation, and carbon emission, respectively.

As it is apparent from previous studies, two of the major determinants of renewable energy consumption are income and carbon emission, so this study investigates the following equation:

$$
L E R_{t}=\mu_{2}+\sum_{j=1}^{p-1} \beta_{2 j} L E R_{t-j}+\sum_{j=1}^{p-1} \gamma_{2 j} L Y_{t-j}+\sum_{j=1}^{p-1} \delta_{2 j} L C_{t-j}+\varepsilon_{2 t}
$$

Carbon emission is also determined by the level of economic activities and by the acceleration of adoption of renewable energy technologies in country. Hence, the following equation completes the three-equation VAR model:

$$
L C_{t}=\mu_{3}+\sum_{j=1}^{p-1} \beta_{3 j} L C_{t-j}+\sum_{j=1}^{p-1} \gamma_{3 j} L Y_{t-j}+\sum_{j=1}^{p-1} \delta_{3 j} L E R_{t-j}+\varepsilon_{3 t}
$$

This study considers annual data of India and China from 1972 to 2011 from World Development Indicators (WDI). Real GDP data have the base year of 2005. Carbon emission data are in kilo tonnes of $\mathrm{CO}_{2}$ emission and renewable energy generation is electricity production from renewable sources $(\mathrm{kWh})$.

The empirical estimation carried out has three objectives. First is to understand how the variables are linked in the long run; second is to find the dynamic causal relationship among the variables; and the third is to investigate the robustness of the causality directions and magnitude. To achieve these objectives a reduced form vector auto regression (VAR) model is constructed with three variables, output, carbon emission, and renewable energy generation. The VAR approach serves the estimation purpose since it avoids imposing structural assumptions by treating all variables as endogenous. The reduced form level VAR is presented as: 


$$
z_{t}=\alpha_{0}+\sum_{j=1}^{p} A_{j} z_{t-j}+\varepsilon_{t}
$$

where, $z_{t}=\left[L Y_{t}, L C_{t}, L E R_{t}\right]$. The series $\mathrm{LY}_{\mathrm{t}}, \mathrm{LC}_{\mathrm{t}}$, and $\mathrm{LER}_{\mathrm{t}}$ can be either $I(0)$ or $I(1) . \alpha_{\mathrm{t}}$ is a vector of constant terms or $\alpha_{0}=\left[\alpha_{Y}, \alpha_{C}, \alpha_{R E}\right]$ and $\mathrm{A}_{\mathrm{j}}$ is a matrix of VAR parameters for lag $j$. The vector of error terms is $\varepsilon_{0}=\left[\varepsilon_{Y}, \varepsilon_{c}, \varepsilon_{R E}\right]^{t} \approx I N(0, \Omega)$.

Before implementing the error correction model it is imperative to ensure first that the underlying data are non-stationary at level and there exists at least one cointegrating relationship among variables. Hence, we implement Augmented Dicky-Fuller (ADF), Phillips Perron (PP) and Kwiatkowski-Phillips-Schmidt-Shin (KPSS) tests for data stationarity. All of these tests indicate that each of the variables for both of the countries follow an I(1) process. However, these standard tests may not be appropriate when the series contains structural breaks (Salim and Bloch, 2009). Therefore, we also employ two structural break tests. Perron (1997) develops a procedure for detecting a single structural break that has been widely used in the literature. For India, Perron's test identifies breaks at 2002, 1998 and 1994 for LIY, LIER AND LIC, respectively. For China, the break dates for LCY, LCER and LCC are 1990, 2001 and 1996, respectively.

More recently, Lee and Strazicich (2003) develop versions of the LM unit root test to accommodate two structural breaks. The endogenous two-break unit root test allows for two shifts in the intercept and is described by $Z_{t}=\left[1, t, D_{l t}, D_{2 t}\right]$, where $D_{j t}=1$ for $t \geq T_{b j}+1, j=$ 1,2 , and zero otherwise. $T_{b j}$ denotes the date of the structural break. Note that the data generating process (DGP) includes breaks under the null $(\beta=1)$ and alternative $(\beta<1)$ hypotheses in a consistent manner. In this model, depending on the value of $\beta$, we have the following null and alternative hypotheses:

$$
\begin{aligned}
& H_{0}: y_{t}=\mu_{0}+d_{1} B_{1 t}+d_{2} B_{2 t}+y_{t-1}+v_{1 t}, \\
& H_{A}: y_{t}=\mu_{0}+\gamma t+d_{1} D_{1 t}+d_{2} D_{2 t}+v_{2 t},
\end{aligned}
$$

where $v_{1 t}$ and $v_{2 t}$ are stationary error terms; $B_{j t}=1$ for $t=T_{b j}+1, j=1,2$ and 0 otherwise. This model can be extended by including two changes in the intercept and the slope and is described by $Z_{t}=\left[1, t, D_{1 b}, D_{2 t}, D T_{1 b}, D T_{2 t}\right]$, where $D T_{j t}=t-T_{b j}$ for $t>T_{b j}+1,{ }_{j}=1,2$ and 0 otherwise. For this extended model the hypotheses are:

$$
\begin{aligned}
& H_{0}: y_{t}=\mu_{0}+d_{1} B_{1 t}+d_{2} B_{2 t}+d_{3} D_{1 t}+d_{4} D_{2 t}+y_{t-1}+v_{1 t}, \\
& H_{A}: y_{t}=\mu_{0}+\gamma t+d_{1} D_{1 t}+d_{2} D_{2 t}+d_{3} D T_{1 t}+d_{4} D T_{2 t}+v_{2 t},
\end{aligned}
$$


where $v_{l t}$ and $v_{2 t}$ are stationary error terms; $B_{j t}=1$ for $t=T_{b j}+1, j=1,2$ and 0 otherwise. We use the method of Lee and and Strazicich (2003) to test the existence of possible structural break.

As Engle and Granger (1987) demonstrate, cointegrated variables must have an error correction representation with an error correction term (ECT) incorporated into the model. Therefore, a vector error correction model (VECM) is formulated to recover the information lost in the differencing process, thereby allowing for long-run equilibrium as well as short-run dynamics. Assuming that there is only one cointegration relationship, the VECM constructed for this study can be expressed as:

$$
\begin{aligned}
& \Delta L Y_{t}=\mu_{1}+\alpha_{11} E C T_{t-1}+\sum_{j=1}^{p-1} \beta_{1 j} \Delta L Y_{t-j}+\sum_{j=1}^{p-1} \gamma_{1 j} \Delta L E R_{t-j}+\sum_{j=1}^{p-1} \delta_{1 j} \Delta L C_{t-j}+\varepsilon_{1 t}, \\
& \Delta L E R_{t}=\mu_{2}+\alpha_{21} E C T_{t-1}+\sum_{j=1}^{p-1} \beta_{2 j} \Delta L E R_{t-j}+\sum_{j=1}^{p-1} \gamma_{2 j} \Delta L Y_{t-j}+\sum_{j=1}^{p-1} \delta_{2 j} \Delta L C_{t-j}+\varepsilon_{2 t}, \\
& \Delta L C_{t}=\mu_{3}+\alpha_{31} E C T_{t-1}+\sum_{j=1}^{p-1} \beta_{3 j} \Delta L C_{t-j}+\sum_{j=1}^{p-1} \gamma_{3 j} \Delta L Y_{t-j}+\sum_{j=1}^{p-1} \delta_{3 j} \Delta L E R_{t-j}+\varepsilon_{3 t},
\end{aligned}
$$

where $\varepsilon_{\mathrm{t}}$ 's are Gaussian residuals applied by Johansen (1991) and $\mathrm{ECT}_{\mathrm{t}-1}=\mathrm{LY}_{\mathrm{t}-1}+\left(\beta_{21} /\right.$ $\left.\beta_{11}\right) \mathrm{LC}_{\mathrm{t}-1}+\left(\beta_{31} / \beta_{11}\right) \mathrm{LER}_{\mathrm{t}-1}$ is the normalized equation. There are two sources of causation, through the ECT if $\alpha \neq 0$, or through the lagged dynamic terms. ECT shows the long-run equilibrium relationship, while the coefficients on the lagged difference terms indicate shortterm dynamics. The statistical significance of negative coefficients associated with ECT provides evidence of the error correction mechanism that drives each variable back to its long-run equilibrium.

Three different causality tests are performed, a short-run Granger non-causality test along with weak exogeneity and strong exogeniety tests. In equation (11), to test $\Delta \mathrm{LY}$ does not Granger cause $\Delta \mathrm{LC}$ in the short run, the statistical significance of the lagged dynamic terms is examined by testing the null $\mathrm{H}_{0}$ : all $\gamma_{i j}=0$ using Wald test. Non-rejection of the null implies $\Delta \mathrm{LY}_{\mathrm{t}}$ does not cause $\Delta \mathrm{LC}$ in the short run. Further, the weak exogeneity test, based on a long-run non-causality test, requires satisfying the null $H_{0}: \alpha_{i j}=0$. It is a likelihood-ratio test which follows a $\chi^{2}$ distribution.

A strong exogeneity test which imposes further restrictions is performed by testing the joint significance of both the lagged dynamic terms and ECT. This requires satisfying both Granger non-causality and existence of weak exogeneity. In particular, $\Delta \mathrm{LY}$ does not cause $\Delta \mathrm{LC}$ if the null $\mathrm{H}_{0}$ : all $\gamma_{\mathrm{ij}}=\alpha_{\mathrm{ij}}=0$ is not rejected. The strong exogeneity test does not 
distinguish between the short-run and long-run causality, but it is a more restrictive test that indicates the overall causality in the system. It is important to highlight that this paper uses the concept of causality in the predictive rather than in the deterministic sense.

\section{Empirical Analysis}

Augmented Dickey-Fuller (ADF), Phillips Perron (PP) and Kwiatkowski-Phillips-SchmidtShin (KPSS) unit root tests are first employed to examine the stationarity of underlying time series data. In Table 3, it is evident that all unit root tests yield similar results: LIY ${ }_{i t}$, LIER $_{i t}$, $\mathrm{LIC}_{i t}, \mathrm{LCY}_{i t}, \mathrm{LCER}_{i t}$, and $\mathrm{LCC}_{i t}$ are non-stationary in their levels but are stationary after taking first difference, so each series is integrated of order one $I(1)$.

Table 3: Unit Root Tests

\begin{tabular}{|c|c|c|c|c|c|c|}
\hline & $\mathrm{ADF}^{\mathrm{a}}$ & & $\mathrm{PP}^{\mathrm{a}}$ & & KPSS $^{\mathrm{b}}$ & \\
\hline Variable & Intercept & $\begin{array}{l}\text { Trend and } \\
\text { Intercept }\end{array}$ & Intercept & $\begin{array}{l}\text { Trend and } \\
\text { Intercept }\end{array}$ & Intercept & $\begin{array}{l}\text { Trend and } \\
\text { Intercept }\end{array}$ \\
\hline \multicolumn{7}{|c|}{ For India } \\
\hline LIY & 2.4804 & -1.1604 & 4.9633 & -1.1604 & $0.7455^{* * *}$ & $0.2144 * *$ \\
\hline$\Delta \mathrm{LIY}$ & $-6.2435 * * *$ & $-7.4883 * * *$ & $-6.2400 * * *$ & $-10.2387 * * *$ & $0.5916^{* *}$ & 0.0786 \\
\hline LIER & -1.1550 & -2.7098 & -1.1381 & -2.8023 & $0.7378 * *$ & $0.0958 * *$ \\
\hline$\Delta \mathrm{LIER}$ & $-6.1911 * * *$ & $-6.1236 * * *$ & $-6.2432 * * *$ & $-6.1697 * * *$ & 0.1075 & 0.0813 \\
\hline LIC & -0.3704 & -1.7125 & -0.3736 & -1.6640 & $-0.7481 * * *$ & $0.1636^{* *}$ \\
\hline$\Delta \mathrm{LIC}$ & $-6.2377 * * *$ & $-6.1975 * * *$ & $-6.2377 * * *$ & $-6.2008 * * *$ & 0.1026 & 0.0922 \\
\hline \multicolumn{7}{|c|}{ For China } \\
\hline LCY & 0.8278 & $-4.7686 * * *$ & 2.0983 & -2.9200 & $0.7442 * * *$ & $0.1363^{*}$ \\
\hline$\Delta \mathrm{LCY}$ & $-3.4762 * *$ &.$-3.5422 *$ & $-3.8775 * * *$ & $-4.2351 * *$ & 0.3299 & $0.1220^{*}$ \\
\hline LCER & 0.8824 & -1.5240 & 0.9672 & -1.7229 & $0.7486^{* * *}$ & $0.1202^{*}$ \\
\hline$\triangle \mathrm{LCER}$ & $-5.4563 * * *$ & $-5.6048 * * *$ & $-5.4563 * * *$ & $-5.5969 * * *$ & 0.1679 & 0.0753 \\
\hline $\mathrm{LCC}$ & 0.07372 & -2.4478 & 0.2874 & -1.8728 & $0.7475^{* * *}$ & 0.0812 \\
\hline$\Delta \mathrm{LCC}$ & $-3.6781 * * *$ & $-3.6585 * *$ & $-3.7058 * * *$ & $-3.6919 * *$ & 0.1058 & 0.0789 \\
\hline
\end{tabular}

As discussed above, this paper employs Lee and Strazicich (2003) test of two structural breaks. This test is superior in terms of power to the widely used Perron (1997) test. The results of this test are provided in Table 4. The results reveal that none of the dates are significant as indicated by $B_{t 1}$ and $B_{t 2}$. Hence, it is concluded that the underlying data are nonstationary at level but stationary at their first differences without there being any statistically significant structural breaks.

As the variables are non-stationary in levels and stationary in first difference, the Johansen (1988) and Johansen and Juselius (1990) maximum likelihood co-integration tests are employed to examine if the variables are cointegrated. The superiority of Johansen's 
approach compared to Engle and Granger's residual based approach lies in the fact that Johansen's approach is capable of detecting multiple cointegrating relationships among variables (Asafu-Adjaye 2000). This study has not applied autoregressive distributed lag (ARDL) approach as the data frame is convincingly large (from 1972 to 2011) and there is no confusion from the unit root tests that all the variables follow a I (1) process. The optimum lag length for both tests as selected by AIC is 4 . The results are reported in Table 5 and show that there is a single cointegration relationship among variables at 5 per cent level of significance in both India and China.

Table 4: LM Two Break Unit Root Tests of Lee and Strazicich (2003)

\begin{tabular}{|c|c|c|c|c|c|c|c|}
\hline Country & Series & $\mathrm{TB}_{1}$ & $\mathrm{~TB}_{2}$ & $k$ & $\mathrm{~S}_{\mathrm{t}-1}$ & $\mathrm{~B}_{\mathrm{t} 1}$ & $\mathrm{~B}_{\mathrm{t} 2}$ \\
\hline \multirow[t]{3}{*}{ India } & LIY & 1978 & 2006 & 0 & $\begin{array}{c}-0.243 \\
(-2.137)\end{array}$ & $\begin{array}{c}-0.046 \\
(-5.048)\end{array}$ & $\begin{array}{c}0.023 \\
(2.4074)\end{array}$ \\
\hline & LIER & 1977 & 2004 & 0 & $\begin{array}{c}-0.458 \\
(-3.133)\end{array}$ & $\begin{array}{c}0.102 \\
(2.900)\end{array}$ & $\begin{array}{c}0.058 \\
(1.673)\end{array}$ \\
\hline & LIC & 1997 & 2000 & 0 & $\begin{array}{c}-0.256 \\
(-2.203)\end{array}$ & $\begin{array}{c}-0.012 \\
(-0.951)\end{array}$ & $\begin{array}{c}-0.020 \\
(-1.556)\end{array}$ \\
\hline \multirow[t]{3}{*}{ China } & LCY & 1975 & 1991 & 0 & $\begin{array}{c}-0.201 \\
(-1.921)\end{array}$ & $\begin{array}{c}-0.047 \\
(-4.150)\end{array}$ & $\begin{array}{c}0.013 \\
(1.155)\end{array}$ \\
\hline & LCER & 1990 & 2003 & 0 & $\begin{array}{c}-0.314 \\
(-2.480)\end{array}$ & $\begin{array}{c}-0.042 \\
(-1.665)\end{array}$ & $\begin{array}{c}0.043 \\
(1.625)\end{array}$ \\
\hline & LCC & 1997 & 2002 & 0 & $\begin{array}{c}-0.167 \\
(-1.738)\end{array}$ & $\begin{array}{c}-0.046 \\
(-2.676)\end{array}$ & $\begin{array}{c}0.051 \\
(2.776)\end{array}$ \\
\hline
\end{tabular}

Note: $\mathrm{TB}_{1}$ and $\mathrm{TB}_{2}$ are the break dates, ${ }_{\mathrm{k}}$ is the lag length, $\mathrm{S}_{\mathrm{t}-1}$ is the coefficient on the unit root parameter and $\mathrm{B}_{\mathrm{t} 1}$ and $\mathrm{B}_{\mathrm{t} 2}$ are the coefficients on the breaks in the intercept. The maximum lag length was set as eight $\left(\mathrm{k}_{\max }=8\right)$, and optimum lag length is selected through 't-sig' approach proposed by Hall (1994). Critical values for the LM test at $10 \%, 5 \%$ and $1 \%$ significant levels are $3.504,-3.842,-4.545$. Critical values for the other coefficients follow the standard normal distribution. $*(* *) * * *$ denote statistical significance at $10 \%, 5 \%$ and $1 \%$.

Table 5: Johansen's Cointegration Test

\begin{tabular}{|c|c|c|c|}
\hline For India: & & & \\
\hline Hypothesized no. of CE(s) & $r=0$ & $r \leq 1$ & $\mathrm{r} \leq 2$ \\
\hline Trace statistic $(\lambda$ trace $)$ & $27.98 * *$ & 11.69 & 8.06 \\
\hline Hypothesized no. of CE(s) & $r=0$ & $r \leq 1$ & $r \leq 2$ \\
\hline Maximum eigenvalue statistic $(\lambda \max )$ & $47.74 * *$ & 19.77 & 8.07 \\
\hline For China: & & & \\
\hline Hypothesized no. of CE(s) & $r=0$ & $r \leq 1$ & $r \leq 2$ \\
\hline Trace statistic $(\lambda$ trace $)$ & $22.229 * *$ & 11.751 & 2.796 \\
\hline Hypothesized no. of CE(s) & $\mathrm{r}=0$ & $r \leq 1$ & $r \leq 2$ \\
\hline Maximum eigenvalue statistic $(\lambda \max )$ & $36.776^{* *}$ & 14.546 & 2.795 \\
\hline
\end{tabular}

The existence of cointegration implies that causality among concerned variables can be detected in at least one direction. However, it does not indicate the direction of the causal relationship. Hence, to understand the direction of causality, ECM-based causality tests are 
performed. The results of these ECM-based causality tests in Table 6 show that in the case of India, there is short short-run causality where renewable energy Granger causes output at 1 per cent level of significance. Also, carbon emission Granger causes both output and renewable energy at 10 per cent level of significance, but there is no short-run causality of carbon emission from either output or renewable energy. These short-run results suggest that the Indian economy clean energy is contributing to output growth, but that growth also depends on carbon emission.

The long-run results in Table 6 for India suggest bidirectional relationships among variables, which indicate that carbon emission, renewable energy and output cause each other in the long run. The long-run causalities are consistent with those found by Salim and Rafiq (2012). Overall, the results for India reveal that renewable energy adoption is positively contributing to the Indian economy in the short run, while increased pressure from emission leads to increased adoption of renewable energy in the long run, which further enhances development of the country.

In China a different picture is revealed. In the short run, output causes renewable energy at 5 per cent level of significance. Hence, economic advances in China contribute to the renewable energy development. However, no reverse direction in causality is evident. In the long run, it is found that output Granger causes both renewable energy and carbon emission, while bidirectional causality is found between carbon emission and renewable energy. Overall, causality in China seems to run from output to renewable energy, with carbon emissions linked in both causal directions with renewable energy production. Therefore, in China it is economic growth that leads to accelerated adoption of renewable energy, both directly and through its impact in reducing carbon emissions.

Table 6: Causality Tests

\begin{tabular}{llll}
\hline Hypothesis & $\begin{array}{l}\text { Short-run Granger } \\
\text { non-causality }\end{array}$ & $\begin{array}{l}\text { Long-run weak } \\
\text { exogeneity test }\end{array}$ & Strong exogeneity test \\
\hline For India & 1.527 & $-1.787^{*}$ & 1.301 \\
$\Delta L Y \rightarrow \Delta L R E$ & 0.004 & $1.942^{*}$ & 0.011 \\
$\Delta L Y \rightarrow \Delta L C$ & $8.089^{* * *}$ & $3.006^{* * *}$ & $4.589^{* * *}$ \\
$\Delta L R E \rightarrow \Delta L Y$ & 0.001 & $1.942^{*}$ & .318 \\
$\Delta L R E \rightarrow \Delta L C$ & $3.414^{*}$ & $3.006^{* * *}$ & $2.808^{*}$ \\
$\Delta L C \rightarrow \Delta L Y$ & $3.603^{*}$ & $-1.787^{*}$ & $3.408^{*}$ \\
$\Delta L C \rightarrow \Delta L R E$ & & & \\
For China & $2.927^{* *}$ & $3.124^{* * *}$ & $5.642^{* *}$ \\
$\Delta L Y \rightarrow \Delta L R E$ & 0.342 & $-2.620^{* *}$ & 0.010 \\
$\Delta L Y \rightarrow \Delta L C$ & 0.331 & -.7591 & 0.184 \\
$\Delta L R E \rightarrow \Delta L Y$ & 0.244 & $-2.620^{* *}$ & 0.583 \\
$\Delta L R E \rightarrow \Delta L C$ & 0.079 & -.7591 & 0.032 \\
$H_{0}: \Delta L C \rightarrow \Delta L Y$ & $3.475^{*}$ & $3.124^{* * *}$ & 2.318 \\
$H_{0}: \Delta L C \rightarrow \Delta L R E$ & Note: $(*),(* *)$ and $(* * *)$ indicate rejection of the null hypothesis of non-causality at $10 \%, 5 \%$ and $1 \%$ level of significance, \\
respectively. All statistical tests are performed using Wald $\chi 2$ tests. &
\end{tabular}




\section{Impulse Response Functions}

Granger causality tests suggest which variables in the models have significant impacts on the future values of each of the other variables in the system. Nevertheless, the results do not, by construction, indicate the direction or duration of these impacts. Variance decomposition (VD) and impulse response functions (IRF) provide this information. Generalized variance decomposition and generalized impulse response functions are calculated from the cointegration results using the methods of Koop et al. (1996), and Pesaran and Shin (1998).

\section{Figure 1: Impulse response functions: India}
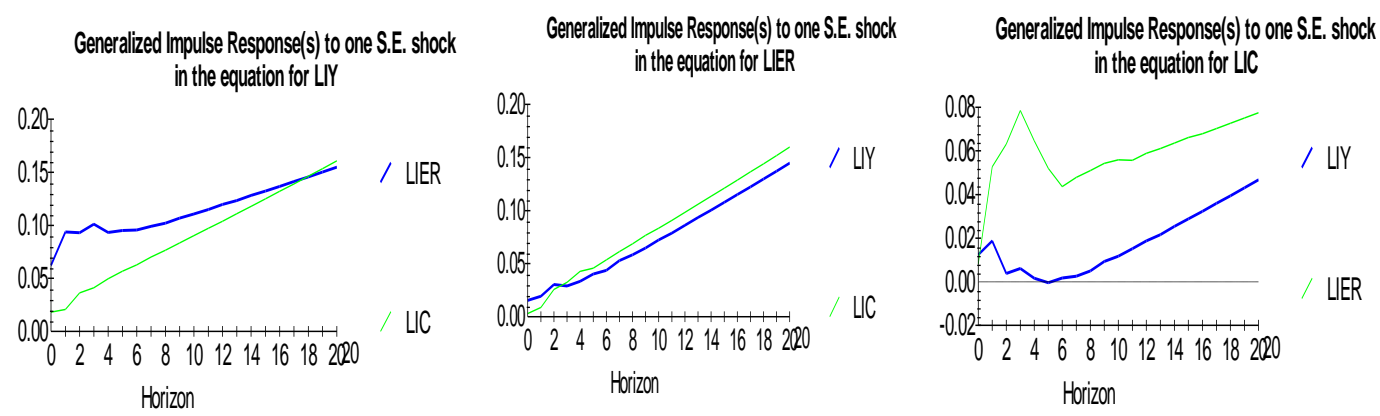

Figure 2: Impulse response functions: China
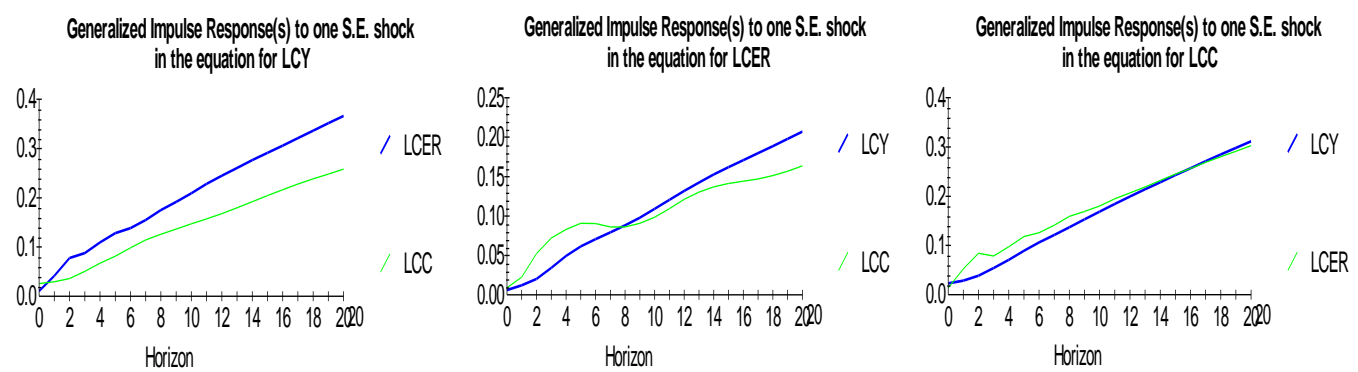

The generalized impulse response functions trace out responsiveness of dependent variables in the VAR to shocks in each of the variables. For each variable from each equation separately, a unit shock is applied to the error, and the effects upon the VAR system over time are noted (Brooks, 2002). Figure 1 for India shows that the LIER response from a one unit standard error (S.E.) shock in the LIY equation is $10 \%$ after two years and, after twenty years, it reaches to $15 \%$, while the response of LIC is $2.5 \%$ after two years and it increase up to $15 \%$ by twenty years. In response to a shock in the equation for LER an almost continual increase of LIY and LIC is revealed. This supports the causality result that LIER and LIC causes LIY. For a shock in the LIC equation, a steady increase in both LIY and LIER occur only after 
some periods of drift or erratic movement. All these results are consistent with the Granger causality result for India that there is bi-directional causality between all the variables.

Figure 2 shows the impulse response functions for China. Shocks in any of the LCY, LCER, or LCC equations lead to fairly steady increases in each of the other variables. These findings support the causality results discussed above and further indicate the positive direction and long duration for the impact of shocks.

\section{Variance Decompositions}

Variance decomposition explains the strength of the movements in each of the dependent variables that is due to its own shocks, contrasted with shocks in the other variables. The effects of these shocks are analysed over a 20 year prospective period in Table 7. In India variations in LIY are initially mostly explained by shocks in the LIY equation, whereas over time shocks to LIER become more important. Shocks to the LIC equation are initially of some importance, but decline in importance over time. Variation in LIER is initially most influenced by shocks in its own equation, with shocks to LIY and LIC of some importance. The importance of shocks to LIY and LIC decline somewhat over time, while shocks to LIER become increasingly important. Variation in LIC is initially mostly explained by its own shocks, but over time shocks to both LIY and LIER rise in importance, eventually surpassing the role of LIC shocks. Overall, the results for India suggest that shocks to economic activities and renewable energy production are more important to the evolution of all variables than shocks to carbon emissions, which opens a role for policy supporting renewable energy investment to reduce emissions without impeding economic activity.

Results in Table 7 show that compared to India shocks to carbon emissions in China are much important in explaining the evolution of all variables in both the short and long run. Shocks to each variable are initially of greatest importance to its own generalized forecast error variance decomposition, but eventually shocks to LCY are of greatest importance and shocks to LCC of second importance in each equation. Shocks to LCER are of much lesser importance in the long run than for either LCY or LCC. Overall, this suggests that in the case

of China direct action to cut carbon emissions has been more important than efforts to increase renewable energy production.

\section{Conclusion}

The main objective of this article is to empirically identify the drivers of renewable energy adoption by examining the dynamic relationship between output, carbon emissions, and renewable energy generation in India and China. This is done by applying a multivariate vector error-correction model to data from 1972 to 2011. Understanding the past causal 
relationships among these variables can provide guidance as to feasible directions for sustainable future development in these rapidly growing economies.

The results of the empirical analysis show that in India there is statistically significant unidirectional short-run causality from carbon emission to both renewable energy generation and output, as well as from renewable energy generation to output. This suggests that renewable technologies are being used to reduce the detrimental impacts of growing emissions while also helping to boost economic growth. In the long run, all the variables have bidirectional causality, which points to the inherent interdependence of growth, energy production and pollution. The picture of renewable energy implementation in India nevertheless shows an encouraging trend as renewable energy technologies are contributing to the sustainable development of the country.

The results for short-run causalities in China show unidirectional relationships running from output to renewable energy and from carbon emission to renewable energy generation. In the long run, the only unidirectional causality is found from output to renewable energy generation, while bidirectional causality is found between carbon emission and renewable energy generation. These results suggest that China has already started to commit its sustainable development through the adoption of cleaner technologies linked to both output and carbon emission growth. However, with the huge environmental degradation caused by human activities in the backdrop, further effort is required through increasing investment in renewable energy sources to help mitigate the adverse effects of carbon emission while sustaining economic growth. 
Table 7: Findings from Generalized Forecast Error Variance Decomposition

a. India

\begin{tabular}{lcccccccccc}
\hline \multirow{2}{*}{ Years } & \multicolumn{3}{c}{ Variance Decomposition of LIY } & \multicolumn{3}{c}{ Variance Decomposition of LIER } & \multicolumn{2}{c}{ Variance Decomposition of LIC } \\
\cline { 2 - 10 } & LIY & LIER & LIC & LIY & LIER & LIC & LIY & LIER & LIC \\
\hline 1 & 0.982 & 0.387 & 0.319 & 0.981 & 0.388 & 0.319 & 0.264 & 0.029 & 0.987 \\
5 & 0.805 & 0.599 & 0.066 & 0.682 & 0.751 & 0.275 & 0.513 & 0.311 & 0.752 \\
10 & 0.756 & 0.721 & 0.026 & 0.715 & 0.782 & 0.229 & 0.606 & 0.463 & 0.606 \\
15 & 0.759 & 0.789 & 0.039 & 0.727 & 0.798 & 0.209 & 0.650 & 0.556 & 0.509 \\
20 & 0.759 & 0.819 & 0.061 & 0.731 & 0.806 & 0.199 & 0.674 & 0.617 & 0.444 \\
\hline
\end{tabular}

b. China

\begin{tabular}{llllllllll}
\hline \multirow{2}{*}{ Years } & \multicolumn{2}{c}{ Variance Decomposition of LCY } & \multicolumn{3}{c}{ Variance Decomposition of LCER } & \multicolumn{3}{c}{ Variance Decomposition of LCC } \\
\cline { 2 - 10 } & LCY & LCER & LCC & LCY & LCER & LCC & LCY & LCER & LCC \\
\hline 1 & 0.972 & 0.374 & 0.272 & 0.181 & 0.843 & 0.651 & 0.340 & 0.129 & 0.966 \\
5 & 0.941 & 0.141 & 0.331 & 0.645 & 0.409 & 0.581 & 0.376 & 0.541 & 0.629 \\
10 & 0.931 & 0.170 & 0.405 & 0.717 & 0.367 & 0.585 & 0.612 & 0.414 & 0.624 \\
15 & 0.918 & 0.191 & 0.439 & 0.767 & 0.327 & 0.575 & 0.676 & 0.383 & 0.612 \\
20 & 0.910 & 0.199 & 0.457 & 0.788 & 0.311 & 0.568 & 0.724 & 0.352 & 0.601 \\
\hline
\end{tabular}

Acknowledgement: We are grateful to the anonymous referee and the editor of this journal for helpful comments and suggestions which tremendously improve the quality and presentation of the paper. However, we alone responsible for any error remain. 


\section{References:}

Ang, J.B., 2007. $\mathrm{CO}_{2}$ emissions, energy consumption, and output in France. Energy Policy 35 (10), $4772-8$.

Apergis, N. and Payne, J.E., 2009. Energy consumption and economic growth in Central America: evidence from a panel cointegration and error correction model. Energy Economics 31, 211216.

Apergis, N. and Tang, C. F., 2013. Is the energy-led growth hypothesis valid? New evidence from a sample of 85 countries. Energy Economics 38, 24-31.

Arouri, M., Youssef, A. B., M., Hatem C. and Rault, C., 2012. Energy consumption, economic growth and $\mathrm{CO}_{2}$ emissions in Middle East and North African countries. Discussion Paper series, Forschungsinstitut zur Zukunft der Arbeit, No. 6412, url:nbn:de:101: 1-201206147237.

Asafu-Adjaye, J., 2000. The relationship between energy consumption, energy prices and economic growth: Time series evidence from Asian developing countries. Energy Economics 22 (6), $615-625$

Bloch, H., Rafiq, S. and Salim, R. A., 2012. Coal consumption, $\mathrm{CO}_{2}$ emission and economic growth in China: Empirical evidence and policy responses. Energy Economics 34, 518-528.

Brooks, C., 2002. Introductory Econometrics for Finance. Cambridge University Press.

Chandran, G. and Tang, C.F., 2013. The dynamic links between $\mathrm{CO}_{2}$ emissions, economic growth and coal consumption in China and India, Applied Energy, 104, 310-318.

Engle, R. F. and Granger, C. W. J., 1987. Cointegration and error correction representation, estimation and testing. Econometrica 55 (1), 26.

Fang, Y., 2011. Economic welfare impacts from renewable energy consumption: the China experience. Renewable Sustainable Energy Rev. 15, 5120-5128.

Ghali, K. H. and El-Sakka, M.I.T., 2004. Energy use and output growth in Canada: A multivariatecointegration analysis. Energy Economics 26 (2), 225-238.

Ghosh, S., 2002. Electricity consumption and economic growth in India. Energy Policy 30 (2), 125129.

Hall, A.D., 1994. Testing for a unit in timeseries with pretest data based model selection. Journal of Business and Economic Statistics 12, 461-70.

Hamit-Haggar, M., 2012. Greenhouse gas emissions, energy consumption and economic growth: A panel cointegration analysis from Canadian industrial sector perspective. Energy Economics $34,358-364$.

Johansen, S. 1988. Statistical analysis of cointegration vectors. Journal of Economic Dynamics and Control 12 (2-3):231-254. 
Johansen, S., 1991. Estimation and hypothesis-testing of cointegration vectors in Gaussian vector autoregressive models. Econometrica 59, 1551-1580.

Johansen, S. and Juselius, K., 1990. Maximum likelihood estimation and inference on cointigration with applications to the demand for money. Oxford Bulletin of Economics \& Statistics 52 (2), $169-210$.

Koop, G., Pesaran, M. H. and Potters, S. M., 1996. Impulse response analysis in nonlinear multivariate models. Journal of Econometrics 74 (1), 119-47.

Kraft, J., and Kraft, A., 1978. On the relationship between energy and GNP. Journal of Energy Development 3,401-403.

Lee, J. and Strazicich, M., 2003. Minimum lagrange multiplier unit root test with two structural breaks. Review of Economics and Statistics 85 (4), 1082-1089.

Liu, X., 2005. Explaining the relationship between $\mathrm{CO}_{2}$ emissions and national income; the role of energy consumption. Economic Letters 87, 325-328.

Ma, H., Oxley, L., Gibson, J. and Kim, B., 2008. China's energy economy: technical change, factor demand and interfactor/interfuel substitution. Energy Economics 30 (5), 2167-2183.

Masih, A. M. M., and Rumi M., 1997. On the temporal causal relationship between energy consumption, real income, and prices: Some new evidence from Asian-energy dependent NICs Based on a multivariate cointegration/vector error-correction approach. Journal of Policy Modeling 19 (4), 417-440.

Minihan, E., S. and Wu, Z., 2012. Economic structure and strategies for greenhouse gas mitigation. Energy Economics 34, 350-357.

Narayan, P. K. and Singh,B., 2007. The electricity consumption and GDP nexus for the Fiji Island. Energy Economics 29 (6), 1141-1150.

Oh, W., and Lee, K., 2004. Causal relationship between energy consumption and GDP revisited: The case of Korea 1970-1999. Energy Economics 26 (1), 51-59.

Pao, H-T. and Tsai, C-M., 2010. $\mathrm{CO}_{2}$ emissions, energy consumption and economic growth in BRIC countries. Energy Policy. 38, 7850-7860.

Pedroni P., 2000. Fully modified OLS for heterogeneous cointegrated panels. Advanced in Econometrics 15, 93-130.

Perron, P., 1997. Further evidence on breaking trend functions in macroeconomic variables. Journal of Econometrics 80 (2), 355-385.

Pesaran, M. H. and Shin, Y., 1998. Generalized impulse response analysis in linear multivariate models. Economics Letters 58, 17-29. 
Rafiq, S.and Salim, R. A., 2011. The linkage between energy consumption and income: A multivariate cointegration analysis in Six Emerging economies of Asia. Journal of Emerging Markets 6 (1), 50-73.

REN21, 2013. Renewables 2013 Global Status Report, REN Secretariate, Paris, France.

Salim, R. A. and Bloch, H., 2009. Business expenditure on R \& D and trade performances in Australia: Is there a link? Applied Economics 41, 351-361.

Salim, R. A. and Rafiq, S., 2012. Why do some emerging economies proactively accelerate the adoption of renewable energy? Energy Economics 34, 1051-1057.

Sadorsky, P., 2009a. Renewable Energy Consumption, CO2 Emissions and Oil Prices in the G7 Countries. Energy Economis 31, 456-462.

Sadorsky, P., 2009b. Renewable energy consumption and income in emerging economies. Energy Policy 37, 4021-4028.

Salamaliki, P. K. and Venetis, I. A., 2013. Energy consumption and real GDP in G-7: Multi-horizon causality testing in the presence of capital stock. Energy Economics 39, 108-121.

Sari, R. and Soytas, U., 2007. The Growth of Income and Energy Consumption in Six Developing Countries. Energy Policy 35 (2), 889-98.

Stern, D. I., 2000. A multivariate cointegration analysis of the role of energy in the US macroeconomy. Energy Economics 22 (2), 267-283.

The World Bank, 2013. Data: Environment. Retrieved February 24, 2013 from http:// www.worldbank.org/S.

The World Bank, 2011. World Development Indicators 2010. Washington, D.C.

The World Bank, 2007. Growth and $\mathrm{CO}_{2}$ emissions: how do different countries fare. Environment Department, Washington, DC.

Wolde-Rufael, Y., 2009. Energy consumption and economic growth: The experience of African countries revisited. Energy Economics 31 (2), 217-224.

Zamani, M., 2007. Energy consumption and economic acivities in Iran. Energy Economics 29 (6), 1135-1140. 